\title{
Linguagem e experienciação cognitiva: da memória corporal à narrativa ${ }^{1}$
}

\author{
Paulo Henrique Aguiar Mendes (UFOP)* \\ Maíra Avelar (UESB)**
}

\begin{abstract}
Resumo
Neste texto, pretendemos abordar a questão das relações entre linguagem e experienciação cognitiva do ponto de vista da sua construção interacional, a partir de práticas discursivas efetivas, que envolvem a corporificação do conhecimento, engendrada em processos multimodais. A integração organismo/ambiente, ecologicamente fundamentada em função de processos intersubjetivos, será focalizada, de modo a destacar a forma como fenômenos relacionados à memória, à intersubjetividade e à construção do self emergem qualitativamente no fluxo narrativo, partilhados durante a interação.

Palavras-chave: Memória corporal. Multimodalidade. Narrativa. Semiótica cognitiva.
\end{abstract}

Recebido em: 08/03/2017

Aceito em: 25/05/2017

1 O presente texto decorre das reflexões desenvolvidas por membros do Grupo de Pesquisa - Complex Cognitio - e depuradas na realização do II Seminário: Linguagem, Cognição e Sistemas Complexos: desafios e propostas para uma metodologia, realizado na PUC Minas, em 2016, e financiado pela CAPES - Auxílio no: 0037/2016 - Processo: 23038.005401/2015-19.

** Universidade Federal de Ouro Preto (UFOP). Docente do Programa de pós-graduação em Letras: Estudos da Linguagem.

*** Universidade Estadual do Sudoeste da Bahia. Docente do Programa de pós-graduação em Linguística. 


\section{Introdução}

Interessa-nos avaliar inicialmente aspectos concernentes à memória corporal (FUCHS, 2012) em suas correlações com a memória cinestésica (SHEETSJOHNSTONE, 2012), atualizadas por meio das narrativas de vida de moradores idosos do distrito de Passagem de Mariana (interior de Minas Gerais), os quais foram entrevistados por pesquisadores da Universidade Federal de Ouro Preto, em pesquisa sobre o patrimônio cultural da região ${ }^{1}$. Tais correlações envolvem o processamento de diferentes níveis de intersubjetividade que serão considerados na análise da coconstrução do self durante as interações em questão.

Para tanto, utilizaremos uma fundamentação teórica cujo escopo converge com aspectos da abordagem da semiótica cognitiva tal como apresentada por Slatev (2012, p.1), a exemplo da busca pela integração entre pesquisa teórica e empírica, da chamada triangulação metodológica e da influência da fenomenologia, entre outras características apontadas por esse autor. Slatev destaca como uma das características da semiótica cognitiva o esforço em prol de um investimento recíproco na construção de modelos teóricos e na observação e análise empírica de fenômenos como a corporificação do conhecimento e da linguagem, a multimodalidade, a metáfora, a intersubjetividade etc. No nosso caso, essa relação recíproca entre reflexão teórica e análise empírica se faz presente, na medida em que buscamos verificar o potencial explicativo de modelos que trabalham com noções específicas de memória, de intersubjetividade e de multimodalidade na análise de um objeto empírico preciso, que se traduz pelas entrevistas anteriormente referidas.

A chamada triangulação metodológica é outro aspecto apontado por Slatev que podemos discutir com base em nosso objeto. Tal triangulação diz respeito ao reconhecimento da validade das chamadas perspectivas de primeira pessoa (subjetiva), de segunda pessoa (intersubjetiva) e de terceira pessoa (objetiva) e à tentativa de conjugá-las na análise de determinados objetos, embora o autor destaque a primazia das perspectivas de primeira e segunda pessoa quando se trata de analisar fenômenos da ordem da significação. A propósito de nosso objeto de pesquisa, é possível problematizá-lo a partir dessas perspectivas, no sentido de que

1 Para mais detalhes sobre a pesquisa desenvolvida com os moradores de Passagem de Mariana pelos membros do GEDEM (Grupo de Estudos sobre Discurso e Memória), ver Mendes \& Mendes (2013). Em função das restrições de espaço e de tempo para a feitura deste artigo, operamos um recorte bastante localizado de um trecho de uma das entrevistas, o qual será analisado. 
se trata de um objeto tipicamente interacional (estritamente dialógico), de modo que prevalece o ponto de vista de segunda pessoa, mas, por outro lado, pressupõe a perspectiva de primeira pessoa, porque o foco da análise são as experiências de vida narradas pelo entrevistado, tal como ele as experiencia na primeira pessoa da enunciação.

Além disso, a entrevista é filmada e, posteriormente, o material é submetido a um tratamento por meio de ferramentas tecnológicas para uma análise pormenorizada, o que implica, de certo modo, um ponto de vista objetivante de terceira pessoa, ainda que não seja predominante e não se trate de uma ilusão ingênua da pura objetividade e da ausência do sujeito (observador). Sendo assim, no que se refere ao nosso objeto, privilegiamos uma abordagem com um viés fenomenológico, a exemplo da concepção de memória corporal (FUCHS, 2012) e cinestésica (SHEETS-JOHNSTONE, 2012) e de prática narrativa (GALLAGHER; HUTTO, 2008), categorias importantes para nossa análise, as quais serão relacionadas às noções de intersubjetividade e construção do self.

\section{Memória e experienciação}

Tendo em vista os objetivos deste texto e os pressupostos teóricos que o fundamentam, faremos um recorte buscando tematizar certos aspectos de uma abordagem mais cognitiva e fenomenológica da memória, sem desconsiderar a validade de outras formulações. Começaremos, então, por considerar a formulação de Fuchs (2012), que relaciona sua noção de memória corporal ao que a psicologia cognitiva categoriza como memória implícita há pelo menos três décadas, embora o autor atribua uma extensão e complexidade maiores à sua formulação. Antes de mencionarmos as dimensões da memória corporal presentes no modelo desse estudioso, vale a pena citarmos uma de suas definições de corpo:

O corpo é, então, o conjunto de predisposições desenvolvidas organicamente e capacidades para perceber e para agir, mas também para desejar e para comunicar. Suas experiências, ancoradas na memória corporal, espalham-se e conectam-se com o ambiente, como uma rede invisível, que nos relaciona às coisas e às pessoas. (FUCHS, 2012, p.11, tradução nossa) ${ }^{2}$

2 The body is thus the ensemble of organically developed predispositions and capacities to perceive and to act, but also to desire and to comunicate. Its experiences, anchored in body memory, spread out and connect with the environment like an invisible network, which relates us to things and to people. (FUCHS, 2012, p.11) 
As formas de memória corporal a que se refere Fuchs (2012, p.12) se traduzem por uma tipologia, a qual representa seis dimensões da experiência corpórea, que, não obstante, se realizam de maneira organicamente integrada. São elas: a memória procedural, a situacional, a intercorporal, a incorporada, a da dor e a traumática. Comentaremos a seguir duas delas, que têm relação mais direta com o nosso objeto de análise, as entrevistas. A memória situacional relaciona-se à integração do corpo ao ambiente espaço-temporal de que participa, proporcionando aos organismos o sentimento de familiaridade ou de estranheza relativo a lugares, conjunturas e situações vividas, com diversas possibilidades de modulação afetiva. A memória intercorporal, por sua vez, reporta-se às formas mais básicas e pré-temáticas de contato com os outros, as quais configuram esquemas intersubjetivos e padrões mais primitivos e gerais de interação.

Podemos fazer ressalvas a essa formulação de Fuchs, no sentido de ser uma taxionomia que pode soar como uma compartimentação meio excessiva que tende a linearizar e engessar processos dinâmicos que funcionam conjuntamente. Mas o próprio autor busca se prevenir contra críticas nessa direção, dizendo, sobre as dimensões descritas acima, que "elas não são estritamente separáveis umas das outras, mas são derivadas de dimensões diferentes da experiência corporal - uma experiência que, entretanto, é um 'ser-para-o-mundo' unitária”. (FUCHS, 2012, p.12, tradução nossa) $)^{3}$.

Há autores que radicalizam a crítica às tipologias de memória em geral, colocando em xeque um pano de fundo epistemológico que as sustentaria e do qual a formulação de Fuchs seria tributária, em última análise. É o caso, por exemplo, de Sheets-Johnstone (2012), para quem a experiência cinestésica, que faz com que organismos animados sejam seres que fundamentalmente se movimentam, está na base da memória corporal e dispensa qualquer tipo de explicação com base em oposições binárias tradicionais. Segundo ela:

Certamente, o fato de que não podemos bloquear a cinestesia coloca em questão os opostos taxonômicos preto-no-branco relativos à memória corporal. A dicotomia consciente/inconsciente não é mais defensável; e nem o são [as dicotomias] implícita/explícita ou procedural/declarativa. A dicotomia episódica/semântica é, no mínimo, suspeita, senão insustentável. Mais do que insustentável

3 They are not strictly separable from each other, but are derived from different dimension of bodily experience - an experience that nevertheless is a unitary 'being-towards-the-world' (FUCHS, 2012, p.12). 
não raramente repousa sobre um fundamento conceitual dicotômico adicional, o que é tomado como um par de oposição incontroverso gerado pela dicotomia mente/corpo ou outra forma parental mencionada acima ${ }^{4}$ (SHEETS-JOHNSTONE, 2012, p. 46, tradução nossa).

Decerto, a autora propõe um questionamento válido sobre em que extensão as categorizações tradicionais dos tipos de memória reproduzem uma concepção dualista, baseada na descontinuidade ontológica entre corpo/espírito, cérebro/ mente e seus correlatos. Essa é uma questão de fundo sobre a qual não vamos nos deter, em função dos objetivos do nosso texto e de sua factibilidade, mas é preciso ressaltar que, ao propor sua tipologia, Fuchs não aposta nesse dualismo, dizendo, aliás, que "a memória do corpo é uma impressiva refutação do dualismo da pura consciência e do corpo físico, pois não pode ser atribuída a nenhum deles" (FUCHS, 2012, p.11, tradução nossa) ${ }^{5}$.

As faculdades da cinestesia e da propiocepção estão, para a autora, no cerne do processo evolucionário, de modo que são filogenética e ontogeneticamente correlacionadas. Há, assim, uma dupla relação de ancoragem cinestésica, no sentido geral de que a memória corporal é baseada na experiência cinestésica graças a padrões da dinâmica do movimento experienciados corporalmente, e no sentido específico de que cada movimento cria uma dinâmica cinestésica distinta em função de suas qualidades enérgico-espaço-temporais. Nas palavras da autora:

A vivacidade é da natureza da vida. Como seres animados, nós nos movemos e, ao nos movermos, articulamos uma dinâmica cinética. Nós o fazemos como adultos em virtude de uma memória cinestésica e, a princípio, em virtude de termos aprendido sobre os nossos corpos e de termos aprendido a nos mover. Pelo fato de os padrões dinâmicos de movimento possuírem qualidades espaciais, temporais e energéticas distintas, cada um deles tem uma forma dinâmica espaço-temporal-energética distinta que é potencialmente invariante, dependendo se praticamos o padrão e, por meio da repetição, o aprendemos (SHEETS-JOHNSTONE, 2012, p. 46, tradução nossa). ${ }^{6}$

4 Surely the fact that we cannot block out kinestesia calls into question black and white taxonomic contraries regarding body memory. The conscious/unconscious dichotomy is no longer tenable; neither is the implicit/explicit or procedural/declarative. The episodic/semantic dichotomy is similarly at the very least suspect if not untenable. More over untenable no infrequently rests on an additional dichotomous conceptual foundation, what is taken as an incontrovertible oppositional pairing genered by the mind/body dichotomy or other such parental form mentioned above. (SHEETS-JOHNSTONE, 2012, p. 46)

5 The memory of the body is an impressive refutation of the dualism of pure consciousness and the physical body, for it cannot be attributed to either of them. (FUCHS, 2012, p.11)

6 Animation is of the nature of life. Being animate beings, we move, and in moving articulate a 
Optamos por tentar articular a formulação de Fuchs (2012) e de SheetsJohnstone (2012), de modo a ponderar as possíveis contribuições de ambas as abordagens para a análise do nosso objeto. Assumimos a hipótese de que a memória cinestésica, no sentido da autora supracitada, possa estar na base da memória corporal como uma dimensão primária que, por ser mais geral e primitiva, não coincide necessariamente com a chamada memória procedural, embora esteja intimamente associada a ela, bem como às outras propostas por Fuchs, a situacional, a intercorporal, a incorporativa, a da dor e a traumática.

Sem negligenciar a relevância dos outros tipos de memória, destacamos neste momento a chamada memória situacional, por tematizar diretamente a questão da espacialização, que nos interessa especialmente, e mais, por ter sido considerada uma categoria extremamente recorrente/saliente em pesquisa empírica de testagem da classificação proposta por Fuchs a partir de entrevistas (KOCH, 2012). Koch afirma que "a memória corporal situacional parece permear todas as outras categorias; existe um aspecto da memória corporal situacional que a torna uma metacategoria para todas as outras categorias" (KOCH, 2012, p. 178, tradução nossa $)^{7}$. Não vamos discutir aqui o teor dessa pesquisa, mas sim relacionar a hipótese acima com o nosso objeto de interesse.

A memória situacional é especialmente significativa, primeiramente, porque nos permite abordar o caráter intrínseco da relação organismo/ambiente não só de um ponto de vista geral e especulativo, mas também de uma perspectiva específica e empírica, no sentido de que nosso objeto é constituído por entrevistas com moradores do distrito de Passagem de Mariana, que falam de suas vidas nesse distrito, enquanto porta-vozes do patrimônio cultural dessa região. Tratase, pois, de um objeto estritamente situado, construído a partir da interação entre pesquisador/entrevistador e morador/entrevistado sobre as situações/experiências vividas por este último em seu próprio nicho biocultural.

Destacamos que as entrevistas foram realizadas justamente nas casas dos moradores, ambiente/nicho por excelência ao qual os entrevistados se sentiam mais

kineticdynamics. We do so as adults in virtue of kinesthetic memory, and, to begin with, in virtue of our having learned our bodies and learned to move ourselves (Sheets-Johnstone, 1999/ expanded $2^{\text {nd }}$ ed. 2011). Because dynamic patterns of movement have distinctive spatial, temporal and energetic qualities, they each have a distinctive spatio-temporal-energetic dynamic form that potentially invariant, depending upon whether we practice the pattern, and through repetition, learn it. (SHEETSJOHNSTONE, 2012, p. 46)

7 situational body memory seems to pervade all the other categories; there is an aspect of situational body memory that make it a meta-category for all the other categories. (KOCH, 2012, p. 178) 
integrados experiencialmente, do ponto de vista da sua constituição identitária e do sentimento de pertença à comunidade, o que, a princípio, configurava um espaço mais propício à emergência das narrativas e, por conseguinte, das representações da memória. É a partir desse eixo situacional/espacial cujo centro é o corpo/casa/ morada que o sujeito engendra, através da sua enunciação, projeções relativas à sua orientação, ao seu deslocamento no espaço/tempo da memória narrativa e, por conseguinte, à constituição de suas ações e relações intersubjetivas, em última instância, à construção interacional de seu self.

\section{Intersubjetividade e narratividade}

A questão da intersubjetividade tem assumido um lugar central nos estudos sobre cognição, ação e linguagem em geral, sendo apontada por diversos pesquisadores como uma capacidade humana singular, que está na base de seus processos corporificados de conhecimento. Nessa perspectiva, ao apresentar um modelo evolucionário e desenvolvimental da intersubjetividade, Slatev (2008, p. 215) a define, em linhas gerais, como "o compartilhamento de experiências afetivas, perceptivas e reflexivas entre dois ou mais sujeitos" $\mathrm{O}$ autor apresenta, em seguida, três características de sua concepção da intersubjetividade: (i) a de não ser uma capacidade unitária/homogênea, no sentido de envolver diferentes formas de consciência, desde a troca de afetos, num nível de empatia, até a partilha de crenças, num nível de estados intencionais, passando pela atenção conjunta; (ii) a de se desenvolver em estágios (na filo e ontogenia), com os mais primitivos servindo de pré-requisitos para os superiores; (iii) a de ser fundamentalmente corporificada, envolvendo uma coexperienciação direta de esquemas corporais.

Ressaltamos aqui a estreita ligação da formulação de Slatev com a dimensão da memória intercorporal proposta por Fuchs, enquanto padrões primitivos e prétemáticos de contato intersubjetivo, e, obviamente, com a memória cinestésica, elaborada por Sheets-Johnstone. Com efeito, Slatev articula as características mencionadas acima à noção de mimese corporal, que configura uma hierarquia de esquemas protomiméticos, miméticos e pós-miméticos, os quais correspondem a diferentes níveis de intersubjetividade.

As formas protomiméticas de intersubjetividade consistem em mapeamentos/ projeções entre esquemas propioceptivos e percepções visuais do outro, sendo associadas pelo autor à noção de esquema corporal, enquanto padrões pré- 
conscientes e, em larga medida, inatos de experienciação (inter)subjetiva. Para Slatev, a habilidade de partilhar afetos, a empatia, é a forma mais básica de intersubjetividade de ordem protomimética, não representacional, seguida por uma segunda forma básica de intersubjetividade protomimética, que se traduz pela capacidade de atenção, no caso de crianças/bebês, segundo o autor.

Os níveis miméticos de intersubjetividade são definidos como diádicos e triádicos, sendo que as formas diádicas de intersubjetividade dizem respeito ao controle atencional consciente dos movimentos do próprio corpo e de suas correspondências com os movimentos de outros corpos durante a interação. $\mathrm{O}$ autor associa essas formas diádicas à noção de imagem corporal, pois envolvem uma consciência plena da distinção entre o self e o não-self, entre o eu e o outro, como seres intencionais distintos, e a capacidade de atenção partilhada e/ou conjunta. Já as formas triádicas de intersubjetividade constituem padrões miméticos mais complexos, que implicam a compreensão recíproca da relação representacional entre os movimentos corporais e os objetos da atenção conjunta dos sujeitos envolvidos na interação.

Sobre a importância dos níveis diádicos e triádicos, Bavelas e outros afirmam que: "os falantes usam gestos para se comunicarem num diálogo, não como indivíduos isolados" (BAVELAS et al, 2001, p. 49, tradução nossa). Ao abordarem os padrões diádicos de interação verbo-gestual, os autores, baseandose em Clark, recorrem à noção de grounding, que corresponde a um processo construído momento a momento na interação, em que os participantes asseguram um ao outro o entendimento mútuo. Um exemplo prototípico de uma grounding sequence ocorre no trecho da entrevista que analisaremos, quando, posteriormente à narração de uma determinada sequência pelo narrador/entrevistado, o pesquisador/entrevistador responde com “Nossa senhora!”, expressando espanto e empatia com o relato do entrevistado e, em seguida, o entrevistado reconhece essa resposta, ao indicar que o entrevistador compreendeu corretamente o que foi dito, por meio de um aceno de cabeça.

Finalmente, as formas pós-miméticas de intersubjetividade são chamadas pelo autor de simbólicas, no sentido de que se referem ao uso de sistemas de signos convencionalizados e/ou institucionalizados, a exemplo das línguas naturais, com sua complexidade estrutural e recursiva. Chegamos a um ponto central de nossa formulação, pois toca diretamente na questão da enunciação, da narratividade e da interação face a face com todos os aspectos fenomenais constitutivos de 
sua complexidade. Nossa hipótese é de que o dispositivo enunciativo, em seu funcionamento dialógico, está na base da semiosfera humana, que, no nosso caso específico, se faz representar pela entrevista, como prática discursiva que emerge a partir da copresença experiencial dos interlocutores, pesquisador-entrevistador e morador-entrevistado.

Trata-se, pois, do que chamamos de experienciação dialogada, cuja natureza multimodal nos leva a considerar, antes de entrarmos numa discussão mais específica sobre os processos desencadeados no excerto da entrevista escolhido para análise, a questão da percepção intersubjetiva. Nesse sentido, cabe ressaltar a abordagem desenvolvida por Gallagher \& Zahavi (2008), que afirmam que nossa experiência não nos relaciona com o outro, seja como terceira pessoa, cuja mente eu tento entender através de inferências teóricas, seja como primeira pessoa, cuja mente eu tento entender através de simulações analógicas, mas com o outro em interação, como segunda pessoa, cujo conhecimento é construído em termos de troca de experiências.

Os autores se propõem a avaliar com mais detalhes a hipótese da simulação implícita, que, segundo eles, ganhou destaque nos últimos anos com os avanços no campo da neurociência. De um ponto de vista neuronal, foi demonstrado que o sistema dos neurônios-espelho está diretamente envolvido na percepção da ação comunicativa. Sendo assim, os neurônios-espelho desempenham um importante papel no estabelecimento de uma ligação entre percepção e ação: eles são ativados quando realizamos uma ação, bem como quando vemos uma ação ser realizada. Consequentemente, "o fato de que as mesmas células estão envolvidas na ação e na percepção sugere que ativar ações em potencial pode ser uma consequência automática da percepção" (HOSTETTER; ALIBALI, 2008, p. 496, tradução nossa). A percepção, então, ativa automaticamente as áreas do cérebro envolvidas em produzir as ações correspondentes. Estudos como esses permitem que seja estabelecida uma correspondência bastante relevante entre gestos e fala, por exemplo, pois: "a mão e a boca estão intimamente coordenadas porque elas são, na verdade, controladas pelo mesmo sistema motor (HOSTETTER; ALIBALI, 2008, p. 505, tradução nossa).

Gallagher e Zahavi questionam a noção de simulação, propondo que as evidências trazidas pela neurociência sejam interpretadas a partir da noção de percepção intersubjetiva: 
Os dados neurocientíficos, entretanto, estão abertos a uma interpretação alternativa e mais parcimoniosa. Poder-se-ia facilmente afirmar que os processos de ressonância neural de que estamos falando, na verdade, fazem parte dos processos subjacentes à percepção intersubjetiva e não à simulação. Ou seja, esses processos têm a ver com uma percepção direta das intenções da outra pessoa, ao invés de se constituírem como um processo mental distinto de simular suas intenções. Essa afirmação requer que concebamos a percepção como um fenômeno temporal, e como enativos, e, portanto, envolvendo processos motores. (GALLAGHER; ZAHAVI, 2008, p. 179, tradução nossa) ${ }^{8}$.

Segundo os autores, em circunstâncias intersubjetivas, os sistemas neurais são ativados na interação com outra pessoa. O outro tem um efeito sobre nós: ele elicita essa ativação. Isso não é uma simulação, mas uma "elicitação perceptual". A natureza dos processos neurais de ressonância envolvidos em nossos encontros intersubjetivos faz com que nossa percepção dos outros seja diferente de nossa percepção de objetos e/ou instrumentos, mas isso não implica que a cognição social seja o resultado de uma simulação implícita. Trata-se, ao contrário, de uma copercepção em nível de intersubjetividade aberta. Gallagher e Zahavi se baseiam no fenomenologista Max Scheler, para quem o argumento da analogia subestima as dificuldades envolvidas na autoexperiência e superestima as dificuldades envolvidas na experiência do outro. Para ele, é preciso reconhecer a natureza corporificada e integrada da autoexperiência e não ignorar o que pode ser diretamente percebido sobre os outros.

A percepção direta do outro se refere, assim, a um nível básico de nossa capacidade de interação por meio de práticas corporificadas, sensório-motoras, constituídas desde a mais tenra infância via mapeamentos/projeções dos movimentos e inflexões dos outros, experienciados a partir de padrões dos nossos próprios esquemas proprioceptivos, o que converge diretamente com as formas protomiméticas de que trata Slatev. Ela serve de base para o desenvolvimento de níveis mais elaborados de nossa capacidade de interação, a partir da qual passamos

8 The neuroscientific data, however, is open to an alternative and more parsimonious interpretation. One could easily claim that the neural resonance processes of which we have been speaking, in fact are part of the processes that underlie intersubjective perception rather than simulation. That is, these processes have to do with a direct perception of the other person's intentions, rather than a distinct mental process of simulating their intentions. This claim requires that we conceive of perception as a temporal phenomenon, and as enactive, and thus as involving motor processes (GALLAGHER \& ZAHAVI, 2008, p. 179). 
a integrar ações em contextos pragmáticos, percebendo os outros como agentes em suas atividades sociais/simbólicas, concepção que se correlaciona às formas miméticas e pós-miméticas propostas por Slatev.

É nesse sentido que Gallagher \& Hutto (2008) postulam três dimensões que estruturam nossas habilidades intersubjetivas de compreensão dos outros: (i) a percepção intersubjetiva; (ii) a compreensão pragmaticamente contextualizada; e (iii) a competência narrativa. Do ponto de vista da ontogênese, os autores afirmam que nossa competência narrativa começa a se desenvolver por volta dos 2 anos de idade e constitui uma forma complexa de conhecer o outro. Segundo eles:

Competência com diferentes tipos de narrativas nos permite entender os outros de variadas maneiras. Diferentes tipos de encontros narrativos são os primeiros a nos permitir desenvolver nossa competência psicológica popular. Hutto (2007, p.53) chama "A Hipótese da Prática Narrativa". Afirma que "as crianças normalmente alcançam a compreensão [psicológica popular] participando de práticas de contar histórias, com o apoio de outras pessoas. As histórias sobre aqueles que agem por razões - isto é, narrativas psicológicas folclóricas - são os focos desta prática. Histórias deste tipo especial fornecem o conjunto de treinamento crucial necessário para entender as razões (GALLAGHER \& HUTTO, 2008, 28, tradução nossa) 9 .

O nosso interesse maior por essa formulação não reside na discussão sobre o desenvolvimento ontogenético das formas de intersubjetividade, nem especificamente em seus padrões de funcionamento na terceira idade, mesmo que os sujeitos entrevistados sejam moradores idosos de Passagem de Mariana. A questão que destacamos é a pertinência desse escopo conceitual em relação a todo o processo de construção das narrativas através do que chamamos de experienciação dialogada, proporcionada pela entrevista. A começar pela dimensão da empatia, como partilha de afetos, é preciso que haja desde o primeiro

9 Competency with diferents kinds of narratives enables us to understand others in a variety of ways. Distinctive kinds of narrative encounters are what first allow us to develop our folk psychological competence. Hutto (2007, p. 53) calls 'The Narrative Practice Hypothesis'. It claims that 'children normally achieve [folk psychological] understanding by engaging in story-telling practices, with the support of others. The stories about those who act for reasons - i.e. folk psychological narratives - are the foci of this practice. Stories of this special kind provide the crucial training set needed for understanding reasons. (GALLAGHER \& HUTTO, 2008, 28). 
contato entre pesquisador/entrevistador e morador/entrevistado uma relação empática a ser construída e gerida durante a interação. É essa relação empática que propicia a emergência da própria narrativa e depende das estratégias de abordagem do pesquisador, no sentido de buscar suscitar a simpatia e a confiança dos moradores, para que eles possam se sentir minimamente à vontade para narrar suas experiências, enquanto representantes do patrimônio imaterial da região.

Nessa perspectiva, a percepção intersubjetiva é uma noção bastante produtiva, pois há de fato uma dimensão experiencial que se estabelece em função do contato corpo a corpo entre os participantes da interação. Há certamente projeções recíprocas de esquemas e imagens corporais bioculturalmente estruturados, cujo processo de coexperienciação, avaliação e validação se dá em presença, em tempo real, no transcorrer da atividade interacional e do fluxo enunciativo. Cabe, no entanto, atentarmos aqui para a dificuldade metodológica em lidar com a complexidade dos fenômenos envolvidos nesse objeto, cuja natureza multimodal é uma de suas principais características. Uma coisa é vivenciar, numa interação multimodal, padrões experienciais miméticos/corporais, outra coisa é desenvolver uma análise minimamente criteriosa desses padrões atualizados através de narrativas orais. Assumir a integridade orgânica da prática discursiva que nos interessa é um desafio que implica a consideração de variáveis linguísticas (verbais), prosódicas e gestuais, na perspectiva da reconstrução interpretativa dos processos enunciativos em questão.

\section{Espacialização e dêixis multimodal}

A problematização das relações entre enunciação, narrativa e memória coloca em pauta a questão de que a memória está em constante trabalho de reconstrução durante a interação; por conseguinte, o acontecimento enunciativo/narrativo opera uma recategorização experiencial dos eventos narrados/rememorados no curso da interação, ou seja, na cena enunciativa que se constrói no presente, que, por sua vez, não é nunca um presente adâmico/inaugural, pois está, de algum modo, estruturado/memorizado sob a forma de padrões corporais, experienciais, interacionais dos participantes, em função de seu nicho biocultural. Buscaremos analisar, então, de que maneira ocorre a emergência das memórias, bem como elucidar alguns padrões multimodais de interação no tipo de entrevista que ora nos interessa. 
Para tanto, selecionamos um fragmento de uma entrevista realizada com o morador Antônio Bonifácio Santiago, de 93 anos. Ele nasceu em Piranga, e mudou-se para Passagem de Mariana com 9 anos, quando começou a trabalhar na Mina da Passagem como "boche" (office boy). O recorte selecionado para análise corresponde ao momento em que o entrevistado narra a sua vinda de Piranga a Passagem. Reiteramos que a experienciação discursiva dialogada é processada de maneira multimodal, adaptando-se às restrições impostas, em tempo real, às atividades corporais dos agentes em interação. Vejamos a seguinte sequência do início da entrevista:

Pesquisador: O senhor veio com sua família pra cá?

Morador: É! Eu vim de Passagem, de Piranga, Piranga.

Pesquisador: É, com seu pai com sua mãe.

Morador: Eu nasci em Piranga.

Pesquisador: Com seu pai ou com sua mãe que o senhor veio?

Morador: Hein?

Pesquisador: $\mathrm{O}$ senhor veio com seu pai ou com sua mãe pra cá?

Morador: Não! O meu irmão (eu vou contar um caso aqui direitinho (risos)). Ó, o meu irmão, traba/ trabaiava aqui, o irmão meu mais véio, ele trabalhava aqui, aqui na Passagem. E ele..Pai falou assim: "Ou”, falou com minha mãe: “É, eu preciso de mandar os trem lá pra/ preciso de mandá os trem lá pra Pedro (ele chamava Pedro). É, e quem é que vai lá?" Mas papai era meio covarde sabe? Deus que me perdoe, porque é meu pai. Mas era meio covarde mandar um minino de nove anos de Piranga aqui. Eu vim a cavalo.

Pesquisador: Sozinho?

Morador: Sozinho! Eu vim a cavalo. Aí, chegou aqui, meu irmão morava aqui em cima aqui. Eu truxe uma garupa de trem, num arreio pra/ mantimento pra ele, num comprar aqui, num ter caderno. Aí, eu cheguei aí, de tarde. Saí lá de Piranga às seis horas da manhã, cheguei aqui quatro hora da tarde, a cavalo. Daqui até lá tem doze légua...

Pesquisador: Nossa senhora!

Morador: Vim, e quando chegou aqui na várzea aqui (...)

Não obstante a heterogeneidade dos estudos sobre narrativa, existe um certo consenso de que a ordem temporal é um critério fundamental para a sua 
caracterização, embora essa ordem não seja suficiente, considerando-se que uma narrativa não é meramente uma sequência de eventos e/ou ações no tempo, mas deve haver uma conexão significativa entre tais eventos/ações de modo a formarem um enredo, uma história, que é narrada a partir de um ou mais pontos de vista ou perspectivas. Faremos um recorte localizado de alguns aspectos da questão em função dos propósitos do nosso artigo. Nesse sentido, destacamos a formulação de Mishler (2002) que afirma que:

O modelo narrativo de tempo enfatiza a importância do contexto na produção de narrativas, ao mostrar como a ordenação temporal é uma função tanto das preferências culturais por histórias bem formadas quanto da natureza situada que caracteriza a atividade de contar histórias, por exemplo, quando geradas em entrevistas ou expressas no curso de conversas em ocorrência natural. (MISHLER, 2002, p. 98).

Ressaltamos aqui o que o próprio autor chama de modelo narrativo/experiencial do tempo, pois essa concepção converge com as dimensões da memória corporal, bem como com os níveis de intersubjetividade que discutimos acima. Antes de entrarmos na análise de elementos relativos ao processamento multimodal do trecho da entrevista/narrativa, comentaremos aspectos mais gerais de sua experienciação discursiva. Assim, é interessante notar que, diante de uma pergunta relacionada à "vinda para Passagem de Mariana com a família", o morador enuncia uma resposta cuja referência é a sua cidade de origem - "Piranga" -. Frente à reiteração da pergunta, reformulada inclusive de modo a restringir o horizonte de resposta, pressupondo que o entrevistado teria vindo com o pai ou com a mãe, o morador lança mão de uma estratégia enunciativa de autorreferenciação da sua própria narrativa, no sentido de estabelecer uma organização discursiva relevante dos eventos narrados, em função da sua interação com o pesquisador, a exemplo do enunciado - “(...) eu vou contar um caso aqui direitinho" -, que propõe um foco atencional conjuntamente processado. A resposta do entrevistado configura um episódio narrativo que se estrutura em torno não só do modo como ele veio de Piranga para Passagem de Mariana - "sozinho, a cavalo" -, mas também das motivações que o trouxeram - trazer mantimentos para o irmão a mando do pai - e da carga afetiva implicada nesse evento narrativo - o ressentimento com relação à covardia do pai, que mandou que ele fosse sozinho aos nove anos de Piranga a Passagem . 
Podemos pontuar sucintamente algumas categorias que nos serviram de fundamentação ao longo deste artigo. Há claramente a emergência de uma dimensão situacional da memória que se constitui na experienciação narrativa, atualizada a partir de um conjunto de coordenadas espaciais orientadas em função do ponto de vista do morador, que enuncia situado em sua própria casa em Passagem, como podemos observar com base nas expressões dêiticas presentes em enunciados como - "Eu vim a cavalo. Aí, chegou aqui, meu irmão morava aqui em cima aqui” - e - “Aí, eu cheguei aí de tarde. Saí lá de Piranga às seis horas da manhã, cheguei aqui quatro hora da tarde, a cavalo, daqui até lá tem doze légua...".

Cabe ressaltar que o processo de narrativização produz uma espacialização da experiência temporal, a qual se traduz, no caso em análise, pela trajetória/ percurso da origem do morador/enunciador (Piranga) até o seu destino (Passagem), o que nos remete, em última análise, aos fundamentos da memória cinestésica, relacionada ao movimento, à propriocepção e à orientação no tempo-espaço. É inevitável relacionar o comentário acima à noção de esquemas imagéticos: "esquemas imagéticos são precisamente essas estruturas básicas de nossa experiência sensório-motora básica pela qual encontramos um mundo que podemos entender e no qual podemos agir." (JOHNSON, 2007, p. 136, tradução nossa). Tais esquemas constituem padrões gestálticos experienciais que emergem no decorrer de atividades sensório-motoras como manipular objetos, se orientar no espaço e tempo e direcionar o foco perceptivo para vários fins. No caso específico acima, temos a presença do esquema imagético da TRAJETóRIA (origem-percursometa) estruturando a narrativa do entrevistado.

A dimensão da memória intercorporal merece também um comentário panorâmico, relacionado aos padrões de intersubjetividade discutidos neste artigo, antes de procedermos a uma análise mais específica da questão da multimodalidade. Podemos dizer que o próprio contato face a face entre entrevistador e entrevistado ativa padrões mnemônicos intercorporais que se manifestam por meio das diferentes formas de intersubjetividade colocadas em jogo. A começar pelos níveis da empatia e da atenção conjuntas necessárias para a manutenção da conversa, em termos de um esforço recíproco para compreender o outro e para se fazer compreender, passando pela manifestação de esquemas miméticos - especialmente de natureza gestual, os quais serão analisados em seguida - até, obviamente, o processamento do nível simbólico de que se constitui 
a própria entrevista, considerando-se inclusive as peculiaridades sócio e idioletais dos parceiros envolvidos na troca verbal. Alguns enunciados da sequência acima indiciam aspectos de tais processos intersubjetivos, como a pergunta inicial do entrevistador, pressupondo a crença de que uma criança viaja geralmente com os pais, a resposta reveladora do entrevistado de que viajou sozinho e de sua mágoa com o pai por isso, seguida da nova pergunta que expressa uma certa surpresa/ espanto do entrevistador - "Sozinho ?"-.

A fim de detalharmos melhor a integração multimodal dos recursos verbais e gestuais, analisaremos separadamente um trecho da sequência da entrevista reproduzida acima, juntamente com a fotografia do curso dos gestos, seguida da descrição da excursão gestual. A excursão gestual compreende três fases (KENDON, 2004, p. 110):

a. a preparação: fase opcional, em que os membros se movem a partir de uma posição de relaxamento ou descanso;

b. o golpe [stroke]: fase obrigatória, em que a expressão gestual é realizada, havendo a manifestação clara de movimentos dinâmicos que demandam esforço e foco de energia. Nesta fase, considerada como o ápice do gesto, as mãos tendem a descrever formas e a completar padrões de movimento; c. a retração: fase opcional, em que há uma retração do movimento para a posição inicial de relaxamento ou descanso.

\section{Figura 1: Fotografias do curso do gesto do excerto 1}

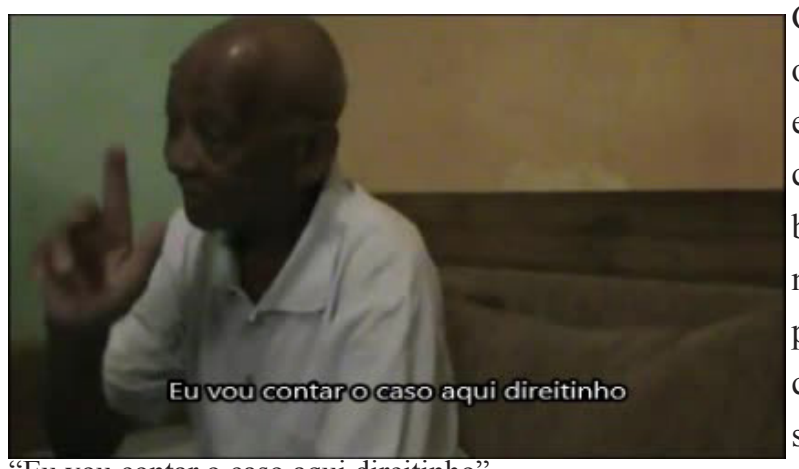

"Eu vou contar o caso aqui direitinho"
Gesto ascendente, com o antebraço posicionado em frente ao corpo, cotovelo apontando para baixo e braço posicionado na vertical. Indicador e polegar apontando para cima e demais dedos semiabertos. 


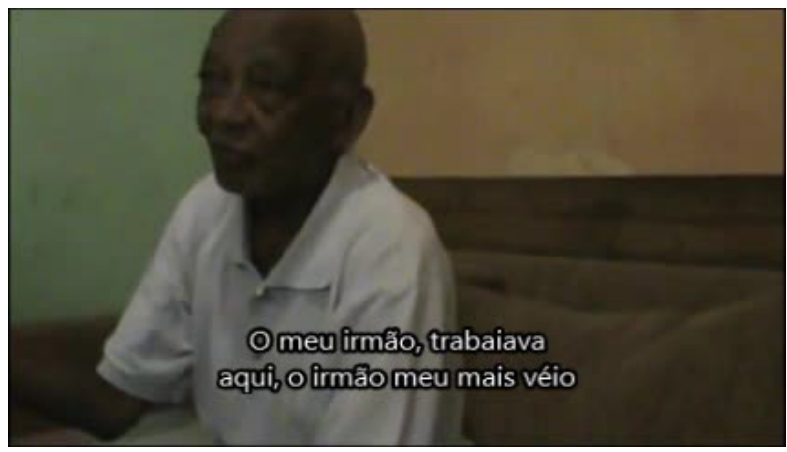

Gesto descendente, com o antebraço pouco à frente do corpo, cotovelo apontando para baixo e braço virado para cima, na horizontal. Não é possível visualizar mão e dedos.

“O meu irmão, trabaiava aqui, o irmão meu mais véio"

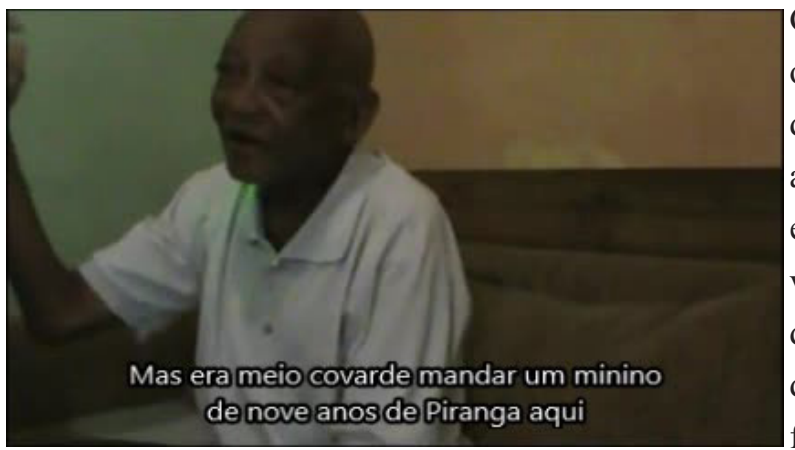

Gesto ascendente, com o antebraço à frente do corpo, cotovelo apontando para baixo e braço posicionado na vertical, virado para dentro. Dedo indicador dobrado e demais dedos fechados.

"Mas era meio covarde mandar um minino de nove anos de Piranga aqui."

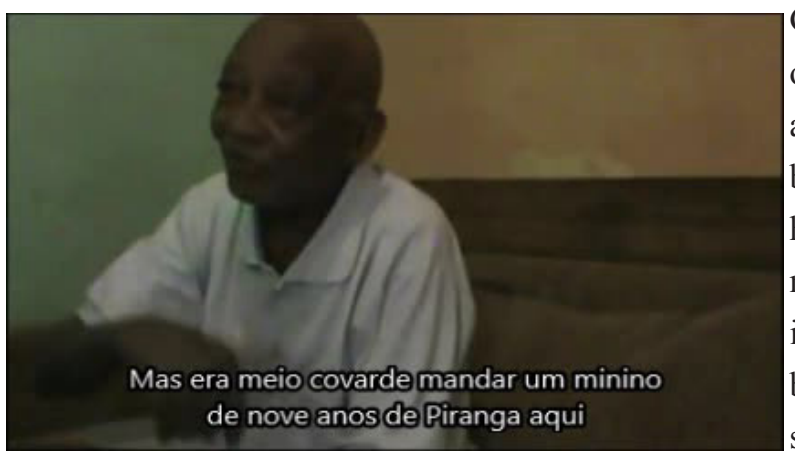

Gesto descendente, com o antebraço posicionado ao lado do corpo e braço posicionado na horizontal. Palma da mão voltada para baixo e indicador apontando para baixo. Demais dedos semiabertos.

\section{Fonte: Entrevista do Banco de Dados do GEDEM/UFOP.}

É possível subdividir os gestos descritos em duas sequências de dois gestos: na primeira sequência, a primeira ocorrência de "aqui", no discurso do entrevistado, remete ao contexto enunciativo imediato: "aqui, nesta entrevista", enquanto a 
segunda ocorrência remete ao distrito em que os interlocutores estão localizados: “aqui, em Passagem". Essa diferença espacial é encenada por meio dos gestos: o primeiro, relativo ao contexto imediato, é realizado mais próximo ao corpo do que o segundo. Além disso, no primeiro gesto, a RETA formada pelo indicador e antebraço pode ser remetida ao domínio conceptual da VERDADE, representada no discurso verbal pelo advérbio "direitinho".

Na segunda sequência, a combinação dos gestos emula espacialmente o Esquema Imagético TRAJETÓRIA, relatado na fala do entrevistado: "de Piranga aqui". O primeiro gesto encena espacialmente o dêitico espacial "lá", mostrando um ponto específico no espaço. O dêitico é especificado como "de Piranga" na fala do entrevistado. O segundo gesto encena espacialmente o dêitico "aqui", também presente no discurso verbal, mostrando um ponto específico no espaço. Em resumo, as duas sequências de gestos apresentam o padrão ascendente-descendente, sendo

que, em ambas as sequências, o uso do indicador demonstra, do ponto de vista corporal, a espacialidade e a proeminência de uso dos dêiticos no discurso - convém lembrar que, etimologicamente, dêixis significa "apontar; mostrar".

Apresentaremos, a seguir, a análise de alguns dados prosódicos, relativos, respectivamente, ao primeiro gesto da primeira sequência e aos dois gestos da segunda sequência gestual:

\section{Figura 2: Prosogramas das sequências 1 e 2}
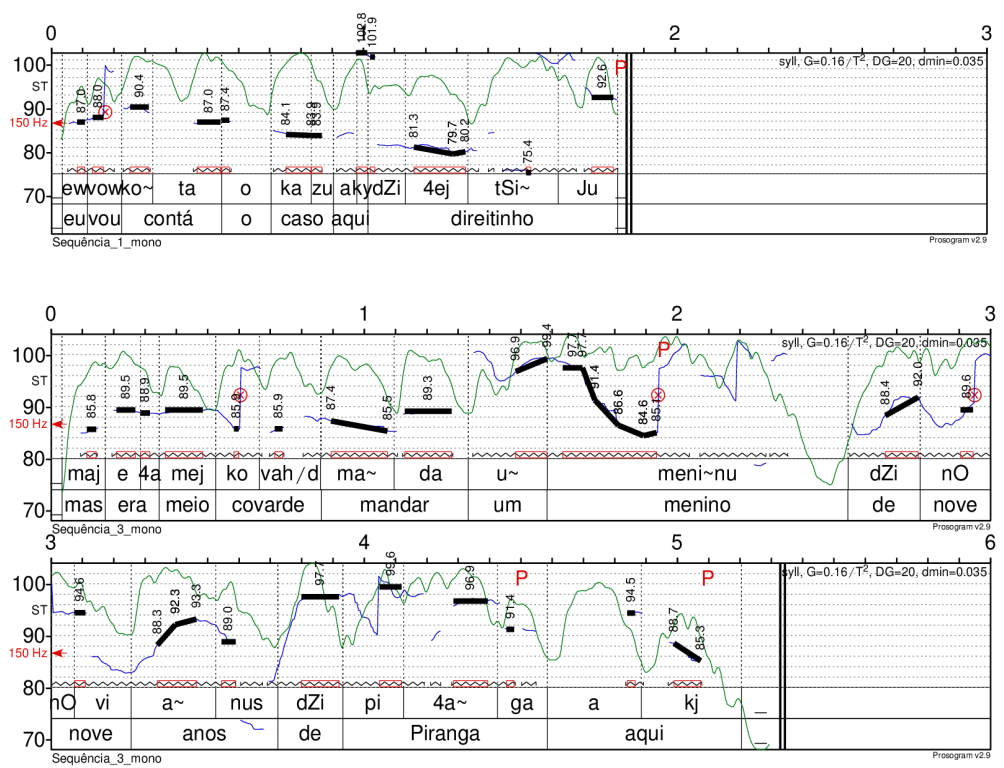

Fonte: Dados da pesquisa 
Quadro 1: Perfis Prosódicos das sequências 1 e 2 do excerto 1

\begin{tabular}{|l|c|c|c|}
\hline \multirow{2}{*}{ Excerto 1 } & Velocidade de fala & Proporção de fonação & Proporção de pausas \\
\cline { 2 - 4 } & 6.62 & 50.78 & 49.22 \\
\hline \multirow{2}{*}{ Sequência 1 } & Velocidade de fala & Proporção de fonação & Proporção de pausas \\
\cline { 2 - 4 } & 6.66 & 100 & 0 \\
\hline \multirow{2}{*}{ Sequência 2 } & Velocidade de fala & Proporção de fonação & Proporção de pausas \\
\cline { 2 - 4 } & 5.27 & 78.5 & 21.5 \\
\hline
\end{tabular}

Fonte: Dados da pesquisa

No primeiro prosograma (MERTENS, 2012) - um plugin que funciona no Praat (BOERSMA \& WEENINK, 2013) -, é possível observar que a curva de F0 - que corresponde aos traços pretos do diagrama - apresenta um perfil descendente, com exceção da última sílaba, que, na verdade, está sobreposta ao início dos risos dos pesquisadores e, por isso, apresenta uma subida correspondente à "explosão" do riso. É necessário, portanto, desconsiderar este trecho. Do ponto de vista quantitativo ver quadro-resumo do perfil prosódico (MERTENS, 2012) do excerto -, é relevante assinalar que não há pausas e que a velocidade de fala no trecho, de 6.66, corresponde à velocidade de fala geral do excerto, de 6.62. Acreditamos que isso se deva ao fato de o trecho corresponder a um parêntese explicativo que o narrador/entrevistado realiza em seu relato: após inserir o tópico "O meu irmão", o narrador/entrevistado interrompe a narrativa para reportar-se aos pesquisadores/entrevistadores e explicar que vai esclarecer como ocorreu a vinda dele de Piranga a Passagem de Mariana. Neste momento, então, ele encena prosodicamente a interrupção da narrativa, por meio da produção de um enunciado com curva descendente e sem pausas - a proporção de fonação é de $100 \%$, enquanto a proporção de pausas é de $0 \%$, conforme pode ser visualizado no quadro em que é apresentado o perfil prosódico da sequência.

A diferença entre o trecho que corresponde à explicação dada aos entrevistadores e os trechos que correspondem ao fluxo da narrativa pode ser mais bem visualizada quando comparamos o primeiro prosograma com o segundo, que corresponde ao trecho em que o entrevistado relata, com ressentimento, a covardia do pai. No trecho em questão, é relevante observar que a curva de $\mathrm{F} 0$ apresenta um perfil mais dinâmico - os traços pretos não são predominantemente planos -, do que no primeiro trecho, especialmente quando o narrador/entrevistado explica "o que" era meio covarde: há um pico de F0, de 98,4 semitons, quando ele diz "um menino", que pode ser percebido como um efeito de ênfase. O mesmo ocorre no trecho "de Piranga": a curva de F0 passa de 85 semitons a 97.7, 99.6 e 96.9 semitons nas sílabas que 
correspondem ao trecho em questão, produzindo, novamente, um efeito de ênfase.

Do ponto de vista quantitativo, - ver quadro-resumo do perfil prosódico do excerto 1 -, é relevante assinalar que há uma diminuição da velocidade de fala da sequência, de 5.27, em relação à velocidade de fala geral do excerto, de 6.62. Isso se reflete, obviamente, na proporção de fonação e de pausas da sequência, de $78.5 \% \mathrm{e}$ $21.5 \%$. As pausas, bem como alguns alongamentos vocálicos, ocorrem em momentos significativos da narrativa: há um alongamento da nasal $[\mathrm{u} \sim]$, que apresenta uma duração total de 285 milissegundos, ou seja, logo no início da primeira ênfase; há também uma pausa entre "um menino" e "de nove anos", de 184 milissegundos; e há uma última entre "de Piranga" e de "aqui", de 686 milissegundos. Os trechos em que as pausas, $\mathrm{o}$ alongamento e as ênfases se apresentam possuem um ritmo bastante constante: cada um deles apresenta quatro sílabas métricas, sendo que a sílaba tônica de todos eles é a última sílaba métrica: um-me-ni-no/ de-no-ve-a-nos/ de-Pi-ran-ga, e há um fechamanto com o "aqui", que apresenta uma curva descendente.

\section{Considerações finais}

Podemos dizer que a experienciação cognitiva e discursiva extrapola os modelos teóricos e os instrumentos metodológicos que tentam explicá-la. Tentamos desenvolver uma análise de aspectos da relação entre memória corporal e narrativa do ponto de vista de sua manifestação intersubjetiva multimodal na entrevista em questão. Para tanto, assumimos a integridade orgânica dessa prática discursiva, buscando avaliar algumas variáveis linguísticas (verbais), prosódicas e gestuais, com vistas a uma reconstrução minimamente consistente de seu processamento, embora saibamos que tivemos que sacrificar nosso desejo de realizar uma análise mais completa e exaustiva da entrevista.

Existem inúmeros outros fatos que mereceriam ser considerados, a exemplo dos desdobramentos enunciativos proporcionados pelo discurso relatado, que configura uma espécie de recursividade dialógica, dos recursos utilizados para guiar as operações atencionais partilhadas pelos interlocutores durante a interação, entre outros fenômenos. Mas isso pode ser objeto de outros trabalhos que irão explorar a imensa riqueza desse material de pesquisa.

Não obstante, podemos dizer que a principal hipótese que atestamos aqui é a de que a discursivização narrativa da memória na interação constitui um processo de reconstrução da experiência vivida, e a identidade se produz como projeção de um holograma experiencial (multimodal) do "eu", em função de sua relação dialógica com o outro. 


\title{
Language and Cognitive Experience: from Body Memory to Narrative
}

\begin{abstract}
This text addresses the relations between language and cognitive experience from the point of view of their interactional construction, by taking into account effective discursive practices that involve knowledge embodiment engendered in multimodal processes. The organism/environment integration, ecologically grounded in function of intersubjective processes will be focused, so as to highlight the ways in which phenomena such as memory, intersubjectivity, and the construction of one's self emerge qualitatively in the narrative flow - and how they are shared during interactions.
\end{abstract}

Keywords: Body Memory. Multimodality. Narrative. Cognitive Semiotics.

\section{Referências}

BAVELAS, Janet et al. Dyadic evidence for grounding with abstract deictic gestures. In: SATAM, Gale \& ISHINO, Mika (Eds.) Integrating Gestures: the Interdisciplinary Nature of Gesture. Amsterdam/Philadelphia: John Benjamins, 2011, p. 49-60.

BOERSMA, Paul \& WEENINK, David. Praat: Doing Phonetics by Computer (Computer program). Version 5.3.60, 2013. Disponível em: $<$ http://www.praat. org/>. Acesso em: 02/12/2013.

FUCHS, Thomas. The phenomenology of body memory. In: KOCH, Sabine; FUCHS, Thomas; SUMMA, Michela; MÜLLER, Cornelia. (Eds.) Body Memory, Metaphor and Movement. Amsterdam/Philadelphia: John Benjamins, 2012, p. 09-23.

GALLAGHER, Shaun \& HUTTO, Daniel. Understanding others through primary interaction and narrative practice. In: ZLATEV, Jordan; RACINE, Timothy; SINHA, Chris; ITKONEN, Esa. The Shared Mind: perspectives on intersubjectivity. Amsterdam/Philadelphia: John Benjamins, 2008, p.17-38.

GAllagher, Shaun \& ZAHAVI, Dan. The Phenomenological Mind: an Introduction to Philosophy of Mind and Cognitive Science. London/New York: Routledge, 2008.

HOSTETTER, Autumn; ALIBALI, Martha. Visible Embodiment: Gestures as Simulated Action. Psychonomic Bulletin \& Review, 15 (3), 2008, p. 495-514. 
JOHNSON, Mark. The Corporeal Roots of Symbolic Meaning. In: The Meaning of The Body: Aesthetics of Human Understanding. Chicago, London: The University of Chicago Press, 1987/2007, p. 135-154.

KENDON, Adam. Gesture Units, Gesture Phrases and Speech. In: Gesture: Visible Action as Utterance. Cambridge: Cambridge University Press, 2004, p. 108-126.

KOCH, 2012. Testing Fuchs' Taxonomy of Body Memory: a Content Analysis of Interview Data. In: KOCH, Sabine; FUCHS, Thomas; SUMMA, Michela; MÜLlER, Cornelia. (Eds.) Body Memory, Metaphor and Movement. Amsterdam/Philadelphia: John Benjamins, 2012, p.171-186.

MENDES, Paulo Henrique A.; MENDES, Simone de Paula. Experienciação, cognição e representações da memória: uma análise discursiva do patrimônio imaterial da Região dos Inconfidentes. Revista de estudos da linguagem. Belo Horizonte, v. 21, n. 1, 2013, p.259-284.

MERTENS, Piet. Prosogram: Transcription of Prosody Using Pitch Contour Stylization Based on a Tonal Perception Model and Automatic or Annotationbased Segmentation (Computer program). Version 2.9, 2012. Disponível em: $<$ http://bach.arts.kuleuven.be/pmertens/prosogram/ >. Acesso em: 02/12/2013.

MISHLER, Elliot. Narrativa e identidade: a mão dupla do tempo. In: MOITA LOPES, Luiz Paulo da; BASTOS, Liliana Cabral (Org.) Identidades: recortes multi e interdisciplinares. Campinas: Mercado das Letras, 2002, p.97-119.

RICOEUR, P. Da memória e da reminiscência. In: RICOEUR, P. A memória, a história, o esquecimento. Tradução de Alain François et al. São Paulo: Campinas. Ed. Unicamp, 2007, p.25-61.

ZLATEV, Jordan. The co-evolution of intersubjectivity an bodily mimesis. In: ZLATEV, Jordan; RACINE, Timothy; SINHA, Chris; ITKONEN, Esa. The Shared Mind: Perspectives on Intersubjectivity. Amsterdam/Philadelphia: John Benjamins, 2008, p.215-244.

ZLATEV, Jordan. Cognitive Semiotics: An emerging field for the transdisciplinary study of meaning. The Public Journal of Semiotics IV (1), October 2012

SHEETS-JOHNSTONE, Maxine. Kinesthetic memory: futher critical reflections and constructive analyses. . In: KOCH, Sabine; FUCHS, Thomas; SUMMA, Michela; MÜLLER, Cornelia. (Eds.) Body Memory, Metaphor and Movement. Amsterdam/Philadelphia: John Benjamins, 2012, p. 43-72. 